\title{
Study of validity of risk of malignancy index in perimenopausal women with ovarian mass in a tertiary care hospital in India
}

\author{
Kalpana Mahadik*, Nandini Singh, M. B. Swami
}

Department of Obstetrics and Gynecology, R. D. Gardi Medical College, Ujjain, Madhya Pradesh, India

Received: 11 November 2019

Accepted: 12 December 2019

\author{
*Correspondence: \\ Dr. Kalpana Mahadik, \\ E-mail: kalpanavmahadik@hotmail.com
}

Copyright: (C) the author(s), publisher and licensee Medip Academy. This is an open-access article distributed under the terms of the Creative Commons Attribution Non-Commercial License, which permits unrestricted non-commercial use, distribution, and reproduction in any medium, provided the original work is properly cited.

\section{ABSTRACT}

Background: Ovarian carcinoma is a silent killer because it presents in advanced stage. In India, it ranks third after carcinoma cervix and breast. Incidence of ovarian cancer is 5.4-8.0 per 100,000 in India. Various versions of risk of malignancy index have been studied to show its validity in different settings. We have studied third version of risk of malignancy index in a resource poor setting in India.

Methods: In this prospective observational study 74 perimenopausal and postmenopausal women with ovarian mass were recruited. Menopausal score (M), Ultrasonography score (U) and CA-125 are components of Risk of Malignancy Index 3. Patients underwent preoperative ultrasonography and CA-125 level was assessed. Scores of M 1-3, U 1-3 and absolute value of CA-125 was multiplied. This product was value of Risk of Malignancy Index 3. If it is less than 250 it suggests absence of malignancy and more than 250 strongly suggests malignancy. Results were confirmed by histopathology.

Results: Fifty six percent women were cancer positive. Ovarian malignancy was more common in postmenopausal age group. Ultrasonography and CA-125 had high sensitivity of $90 \%$ but poor specificity. Risk of malignancy index 3 had a sensitivity, specificity, positive predictive value and negative predictive value of $90 \%, 91 \%, 78 \%$ and $96 \%$ respectively at a cut off value of 250 .

Conclusions: Risk of malignancy index was concluded to be a multimodal approach with better diagnostic scoring index in preoperative stage in women of ovarian masses. It is simple and easily applicable clinical tool in resource poor setting.

Keywords: Menopause, Ovarian cancer, Risk of malignancy index, Serum CA-125, Ultrasonography in carcinoma ovary

\section{INTRODUCTION}

Ovarian cancer is the most lethal malignancy as $70 \%$ are diagnosed only in advanced stage. ${ }^{1}$ The lifetime risk of ovarian cancer in women is $1 \%$ to $1.5 \%$. It has the highest case fatality ratio of all gynaecological malignancies. ${ }^{2}$ In India, ovarian cancer (OC) ranks third after carcinoma cervix and breast in most of the population-based cancer registries. Age-adjusted incidence rates of ovarian cancer vary between 5.4 and 8.0 per 100,000 population in different parts of our country. ${ }^{3}$ Projected number of cases for this cancer for
2015 and 2020 are 45,231 and 59,276, respectively. ${ }^{4}$ This statistic efficiently demonstrates OC as a major concern. Preoperative detection of $\mathrm{OC}$ is a challenge in the eyes of gynaecologist as the anatomical location of the ovary is deep into the peritoneum which makes them less accessible for satisfactory screening test unlike cervix, endometrium and breast which can be easily examined. Vague presenting symptoms, low prevalence and contraindication of biopsy as it can lead to dissemination of tumour cells and change in surgical staging further enhance the difficulty. Preoperative detection is imperative from intervention point of view because in 
stage Ia (FIGO 2014) ovarian tumour the cure rate is more than $80 \% .^{5}$ Moreover, it will prevent morbid surgeries and cost of therapy in benign ovarian tumour. The screening tests available are tumour markers (CA125), Ultrasonography (USG), multimodality screening (CA-125 followed by USG), CT scan and MRI. CA-125 elevation is significant in postmenopausal age group as it may be falsely elevated in benign conditions in premenopausal women. The prostate, lung, colorectal and ovarian cancer screening (PLCO) trial concluded its positive predictive value as $<4 \%$ which is unacceptable for screening test of $\mathrm{OC}$ and thus US preventive services task force gave it the lowest ranking. ${ }^{6,7}$ Various morphological features in USG are suggestive of malignancy like irregular solid mass or multilocular cystic mass, solid components, papillary projections on the cyst wall, ascites, peritoneal nodules and any evidence of metastases. Papillary projections are defined as small solid areas projecting $\geq 3 \mathrm{~mm}$ from the cyst wall. $^{8}$

In a health care resource limited developing country like India we need to adopt a feasible and economical screening test which identifies $\mathrm{OC}$ and differentiate between benign and malignant ovarian neoplasm. Risk of malignancy index (RMI) is a scoring system which was first introduced by Jacob et al in 1990 as RMI1. ${ }^{9}$ It was modified by Tingulsted in 1996 which was named as RMI2 and later in 1999 as RMI3. ${ }^{10,11}$ The difference between the three indices lies in the different scoring of ultrasound parameters and menopausal status. It incorporates absolute value of CA-125, USG and menopausal status in preoperative period for the likelihood of ovarian malignancy. Through this study we intend to evaluate the validity of RMI 3 in its application in daily clinical practise to facilitate screening in women suspected with pelvic mass, to plan appropriate treatment protocol and triage management.

\section{METHODS}

This was a prospective observational study conducted at department of obstetrics and gynecology, R.D. Gardi Medical College Ujjain from 2017 to 2019. Seventy-four perimenopausal and postmenopausal women who were clinically diagnosed as pelvic tumour were recruited in the study. Patients who were unfit for surgery due to medical comorbidities and OC in advanced stage were excluded. Detailed clinical history was taken pertaining to age, parity, symptoms, menstrual history and consumption of oral contraceptive pills (OCPs) for more than five years. After recording demographic information, general examination with height and weight was recorded to calculate body mass index (BMI). BMI is the metric currently in use for defining anthropometric height/weight characteristics in adults and for classifying them into groups. ${ }^{12}$ It is calculated as weight $(\mathrm{kg}) /$ height $\mathrm{x}$ height $\left(\mathrm{m}^{2}\right)$ and the patients were categorized into underweight $\left(>18 \mathrm{~kg} / \mathrm{m}^{2}\right)$, normal weight (18-24.9 $\mathrm{kg} / \mathrm{m}^{2}$ ), overweight $\left(24.9-29.9 \mathrm{~kg} / \mathrm{m}^{2}\right)$ and obese (> 30 $\mathrm{kg} / \mathrm{m}^{2}$ ). Thorough clinical examination was performed to derive provisional diagnosis. In all women serum CA-125 estimation was done. Ultrasonography (abdomen and pelvis) was performed with full bladder technique with 3$5 \mathrm{MHz}$ probe frequency by an experienced radiologist. Based on these three parameters RMI was calculated.

\section{Ultrasound scoring $(U)$}

It was based on one point for each of the following bilateral lesion, multilocular cyst, solid areas, evidence of metastasis and ascites. Among them solid component is the most significant predictor of malignancy. ${ }^{13,14}$ Cystic ovarian mass with septa is a strong evidence of neoplasm and if it measures $>2-3 \mathrm{~mm}$ is suggestive of malignancy. ${ }^{10}$ For RMI, $\mathrm{U}=1$ for ultrasound point $0 / 1, \mathrm{U}$ $=3$ for ultrasound point $\geqq 2$. Ultrasound scoring was done one week prior to laparotomy.

\section{Serum CA-125 level estimation}

Peripheral venous blood sample $(5 \mathrm{ml})$ was withdrawn from each patient prior to surgery for estimation of serum CA-125 level. It was determined by radioimmunoassay using 2 monoclonal antibodies with specificities against CA-125's two major antigenic domains, OC125 and M11.5 (VITROS ECi/ECiQ/3600 Immunodiagnostic systems and the VITROS 5600/XT 7600 integrated systems). The cut off value of CA-125 was accepted as $35 \mathrm{IU} / \mathrm{ml}$ as the upper limit of normal (ULN). ${ }^{15}$

\section{Menopausal scoring (M)}

Postmenopausal status was defined as more than one year of amenorrhea or an age of 50 years in women who had hysterectomy while all other women were considered premenopausal. For premenopausal women $\mathrm{M}=1$ and for postmenopausal women $\mathrm{M}=3$. RMI was calculated for each subject

$$
\mathrm{RMI}=\mathrm{M} \times \mathrm{U} \times \mathrm{CA}-125(\mathrm{U} / \mathrm{ml})
$$

Operative finding during surgery of all cases were obtained. Specimen was sent for histopathology in the department of pathology. Histopathology was considered the gold standard for defining the outcomes. ${ }^{16}$ Results of RMI were validated against histopathology confirmed malignancies.

\section{Statistical analysis}

Statistical analysis was done using SPSS (Statistical Package for Social Sciences) Version 23.0 statistical Analysis Software. Chi square test was used for data analysis. Univariate analysis to determine the association of each parameter was performed using Student's t test. The predictive power of each factor and their combinations were assessed by the goodness of fit test at $1 \%$ significance. To determine the best cut off value to differentiate between benign and malignant pelvic mass, 
receiver operating characteristic curves (ROC) of CA-125 and RMI were plotted. The best cut off was chosen according to the highest sensitivity with the lowest falsepositive rate. Diagnostic performances of each test were reported as sensitivity, specificity, positive predictive value (PPV), and negative predictive value (NPV) with 95\% confidence interval. Sensitivity is the percentage of patients with malignant ovarian mass having a positive test result. Specificity is the percentage with benign ovarian mass showing negative results. Positive predictive value is the percentage of patients with a positive test result having malignant ovarian mass.
Negative predictive value is the percentage of patients with a negative test result having benign ovarian mass, $\mathrm{p}$ value $<0.05$ was considered to be significant.

\section{RESULTS}

A total of 74 perimenopusal and postmenopausal women with pelvic tumour suspected to be ovarian neoplasm were enrolled. Based on histopathological examination of the specimen after surgery 54 patients $(72.9 \%)$ had benign tumour and 20 patients $(27 \%)$ had malignant tumour.

Table 1: Clinical profile of study participants and their distribution as benign and malignant tumor.

\begin{tabular}{|c|c|c|c|c|}
\hline \multirow{2}{*}{\multicolumn{2}{|c|}{ Characteristics of study participants }} & \multicolumn{2}{|l|}{ Histopathology } & \multirow{4}{*}{$\begin{array}{l}\mathrm{p} \text {-value } \\
\mathrm{p}=0.012\end{array}$} \\
\hline & & Benign $(n=54)$ & Malignant $(n=20)$ & \\
\hline \multirow{2}{*}{ Age (years) } & $\leq 50(\mathrm{n}=53)$ & $81.1 \%(43)$ & $18.9 \%(10)$ & \\
\hline & $>50(n=21)$ & $52.4 \%(11)$ & $47.6 \%(10)$ & \\
\hline \multirow{2}{*}{ Parity } & Nulliparous $(\mathrm{n}=6)$ & $33.3 \%(2)$ & $66.7 \%(4)$ & \multirow{2}{*}{$\mathrm{p}=0.02$} \\
\hline & Multiparous $(n=68)$ & $76.5 \%(52)$ & $23.5 \%(16)$ & \\
\hline \multirow{2}{*}{ OCP use } & Yes $(n=15)$ & $93.3 \%(14)$ & $6.7 \%(1)$ & \multirow{2}{*}{$\mathrm{p}=0.041$} \\
\hline & No $(n=59)$ & $67.8 \%(40)$ & $32.2 \%(19)$ & \\
\hline \multirow{4}{*}{ BMI } & Underweight $(\mathrm{n}=5)$ & $80 \%(4)$ & $20 \%(1)$ & \multirow{4}{*}{$\mathrm{p}=0.399$} \\
\hline & Normal weight $(n=33)$ & $81.8 \%(27)$ & $18.2 \%(6)$ & \\
\hline & Overweight $(\mathrm{n}=33)$ & $63.6 \%(21)$ & $36.4 \%(12)$ & \\
\hline & Obese $(n=3)$ & $66.7 \%(2)$ & $33.3 \%(1)$ & \\
\hline
\end{tabular}

Table 2: Correlation of RMI and its individual parameter with histopathology.

\begin{tabular}{|c|c|c|c|c|}
\hline \multirow[t]{2}{*}{ Parameter } & & \multicolumn{2}{|c|}{ Histopathology } & \multirow[t]{2}{*}{ p-value } \\
\hline & & Benign & Malignant & \\
\hline \multirow{2}{*}{ Menstrual status (M) } & $1(n=45)$ & $84.4 \%(38)$ & $15.6 \%(7)$ & $\mathrm{p}=0.006$ \\
\hline & $3(n=29)$ & $55.2 \%(16)$ & $44.8 \%(13)$ & \\
\hline \multirow{2}{*}{ CA-125 (IU/ml) } & $<35(\mathrm{n}=42)$ & $95.2 \%(40)$ & $4.8 \%(2)$ & $\mathrm{p}=0.000$ \\
\hline & $>35(n=32)$ & $43.8 \%(14)$ & $56.3 \%(18)$ & \\
\hline \multirow{2}{*}{ USG Score (U) } & $1(n=32)$ & $93.8 \%(30)$ & $6.3 \%(2)$ & $\mathrm{p}=0.000$ \\
\hline & $3(n=42)$ & $57.1 \%(24)$ & $42.8 \%(18)$ & \\
\hline \multirow{2}{*}{ RMI } & $<250(\mathrm{n}=51)$ & $96.1 \%(49)$ & $3.9 \%(2)$ & $\mathrm{p}=0.000$ \\
\hline & $>250(n=23)$ & $21.7 \%(5)$ & $78.3 \%(18)$ & \\
\hline
\end{tabular}

According to (Table 1) the study included 53 patients with age $<50$ years and 21 patients with age $>50$ years. OC was seen in $47.6 \%$ among patients > 50 years and $18.9 \%$ in patients with age $<50$ years. The occurrence of OC in the age group $>50$ years is statistically significant $(\mathrm{p}=0.012)$ demonstrating that ovarian tumour in advanced age is more likely to be malignant. Number of nullipara women in our study were 6 and multipara were 68. The percentage of OC was $66.7 \%$ (4) in nullipara and $23.5 \%$ (16) in multipara women. Our study comprised of 15 patients who were consuming OCPs for $>5$ years and 59 patients who did not use OCPs or consumed it for less than 5 years. Malignancy was seen in $32.2 \%$ (19) of patients who did not use OCPs or used it for less than 5 years and only in $6.7 \%$ (1) of patients who were on OCPs for $>5$ years. Statistically it is shown that both number of pregnancies $(\mathrm{p}=0.02)$ and use of OCPs $>5$ years $(\mathrm{p}=0.041)$ are protective factors for OC. There were 5 patients in the underweight category, 33 patients of normal weight, 33 patients in overweight category and 3 patients in obese category. OC was seen in $20 \%$ (1) of underweight patients, $18.2 \%$ (6) of normal BMI, $36.4 \%$ (12) of overweight and $33 \%$ (1) of obese patients. This data was statistically insignificant $(\mathrm{p}=0.399)$.

Table 2 shows in our study 29 patients were postmenopausal and 45 were premenopausal. Ovarian malignancy was detected in $44.8 \%$ (13) of 
postmenopausal women and $15.6 \%$ (7) of premenopausal patients. Statistically it was shown that malignancy was more common in postmenopausal group $(p=0.006)$. The CA-125 is analysed with a cut off value of $35 \mathrm{U} / \mathrm{ml}$. The normal range is $0-35 \mathrm{U} / \mathrm{ml}$. Out of 32 patients with CA$125>35 \mathrm{U} / \mathrm{ml}, 56.3 \%$ (18) were malignant and $43.8 \%$ (14) patients had benign ovarian tumour. Among 42 patients with CA-125 < $35 \mathrm{U} / \mathrm{ml}, 95.2 \%$ (40) were benign and $4.8 \%$ (2) were ovarian malignancy. It is statistically significant that CA-125 below it cut off clearly demarks the benign nature of ovarian mass but it elevation $>35$ $\mathrm{IU} / \mathrm{ml}$ is inconclusive $(\mathrm{p}=0.000)$. There were 32 patients with $\mathrm{U}=1$ while 42 patients with $\mathrm{U}=3$. Among patients with $\mathrm{U}=3,42.9 \%$ (18) were malignant and $57.1 \%$ (24) were benign while patients with $U=1,6.3 \%$ (2) had OC and $93.8 \%$ (30) had benign ovarian tumour. It was statistically significant $(\mathrm{P}=0.000)$. With the cut off value of 250, 51 patients had RMI $<250$ and 23 patients had RMI > 250. With RMI < 250, 96.1\% (49) patients had benign ovarian tumour and $3.9 \%$ (2) had OC and patients with RMI > 250 have $21.7 \%$ (5) had benign neoplasm and $78.3 \%$ (18) of patients had OC. It is statistically significant $(\mathrm{p}=0.000)$.

Table 3: Diagnostic efficacy of individual parameter of RMI and RMI as marker of malignancy in histopathology positive malignant patients.

\begin{tabular}{|lllll|}
\hline Measures & $\mathbf{U} \geq \mathbf{3}(\mathbf{\%})$ & $\mathbf{C A}-\mathbf{1 2 5} \geq \mathbf{3 5} \mathbf{I U} / \mathbf{m l}(\mathbf{\%})$ & $\mathbf{M} \geq \mathbf{3}(\%)$ & $\mathbf{R M I} \geq \mathbf{2 5 0}(\%)$ \\
\hline Sensitivity & 90 & 90 & 65 & 90 \\
\hline Specificity & 56 & 74 & 70 & 91 \\
\hline Positive predictive value (PPV) & 43 & 56 & 45 & $\mathbf{7 8}$ \\
\hline Negative predictive value (NPV) & 94 & 95 & 84 & 96 \\
\hline False positive rate & 44 & 26 & 30 & 9 \\
\hline False negative rate & 10 & 10 & 35 & 10 \\
\hline Diagnostic accuracy & 65 & 78 & 69 & 91 \\
\hline
\end{tabular}

Table 4: Area under the curve.

\begin{tabular}{|lccccc|}
\hline Test result variable(s) & Area & Std. Error & Asymptotic Sig. & \multicolumn{2}{c|}{$\begin{array}{l}\text { Asymptotic 95\% confidence interval } \\
\text { Lower bound }\end{array}$} \\
\hline RMI & .918 & .045 & .000 & .829 & 1.000 \\
\hline CA-125 & .860 & .056 & .000 & .751 & .970 \\
\hline
\end{tabular}

${ }^{\mathrm{a} U n d e r}$ the nonparametric assumption, ${ }^{\mathrm{b}} \mathrm{Null}$ hypothesis: true area $=0.5$.

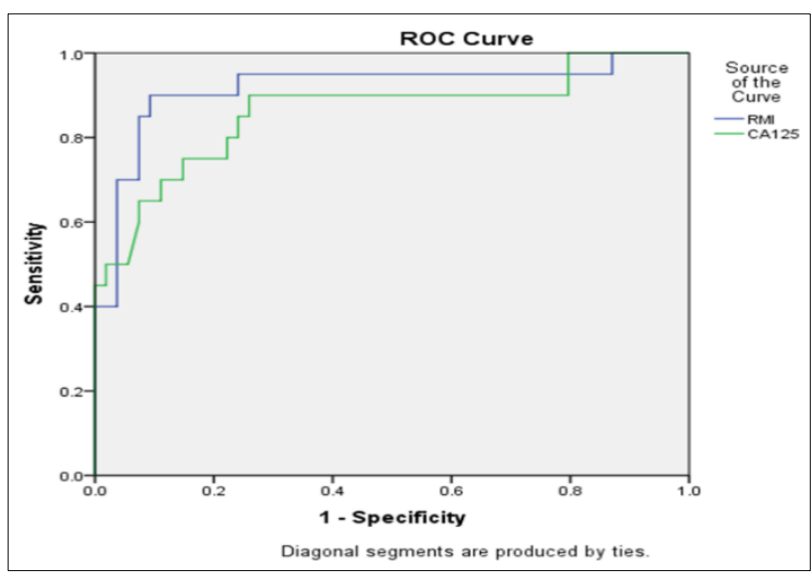

Figure 1: Receiver operating characteristic curves of RMI and CA-125 for predicting malignancy.

Table 3 demonstrate that the sensitivity of menopausal score in our study was $65 \%$, specificity $70 \%$, PPV $45 \%$ but had a high NPV of $84 \%$ with the accuracy of $69 \%$. The sensitivity of ultrasound in differentiating benign and malignant tumor was $90 \%$, specificity $56 \%$, PPV $43 \%$,
NPV 94\% and accuracy $65 \%$. The sensitivity of CA-125 with a cut off value of $35 \mathrm{U} / \mathrm{ml}$ was $90 \%$, specificity 74\%, PPV 56\% and NPV 95\% with the diagnostic accuracy of $78 \%$. The sensitivity and NPV of CA-125 and USG is comparable in diagnosing OC. The sensitivity, specificity, PPV and NPV of RMI at cut off value of 250 were $90 \%, 91 \%, 78 \%, 96 \%$ respectively. We found that RMI has the maximum diagnostic accuracy of $91 \%$ and better performance than the individual parameter i.e. CA 125, ultrasound score and menopausal score as a predictor of OC.

Figure 1 depicts the ROC curves of RMI and CA125.The performance of CA-125 and RMI is shown in ROC curves. Area under cover in ROC determines the diagnostic power of test. The curve is obtained from sensitivity versus specificity. Its application for evaluation of a screening test for differentiating benign and malignant mass is based on this curve. The cut-off point is the shortest distance between peak of the curve and point 1 . Best performance of CA-125 was seen at level of $35 \mathrm{IU} / \mathrm{ml}$ (highest area under the ROC curves i.e. $86 \%$ ). As we increase the cut off value specificity increase but the sensitivity decreases. The best 
performance obtained for RMI was at the cut off of 250 . There was $91 \%$ increase in the odds of diagnosing OC with use of RMI when compared to not using RMI. Taking into account the best obtained cut-off point for RMI, 5 cases were false positive (RMI $\geq 250$ benign tumours) among which $60 \%$ (3) was contributed by serous cystadenoma and $40 \%$ (2) by the mucinous cystadenoma. Eighteen cases were true positive (RMI $\geq$ 250 malignant tumours) while 49 cases were true negative (RMI $<250$ benign tumours) and 2 cases were false negative (RMI < 250 malignant tumours), that were mucinous cystadenocarcinoma.

\section{DISCUSSION}

This study addresses validity of RMI- version 3 to correlate presumptive diagnosis of ovarian carcinoma in women of perimenopausal and postmenopausal age having ovarian masses. As five-year survival in stage Ia is $80 \%$ we assume that this score will help in preoperative provisional diagnosis with early intervention. ${ }^{5}$ The most common benign ovarian tumour was serous cystadenoma and malignant $\mathrm{OC}$ was serous cystadenocarcinoma.

Mean age of women in this study for OC was 47.36 years. This study shows that among nulliparous women $66.7 \%$ had malignant tumour when compared to $23.5 \%$ in multiparous women $(\mathrm{p}=0.012)$. It is concluded that nullipara have higher incidence compared to multipara. Pregnancy causes anovulation and suppresses secretion of pituitary gonadotropins. Each full-term pregnancy lowers risk by approximately $15 \% \cdot{ }^{17,18}$ Studies in African, American and Asian populations have yielded similar results. ${ }^{19,20}$ While considering relation of OC to contraceptive pills our findings are consistent with other authors. $^{21}$ The protective effect of OCP on OC is an interesting finding. As such OCP use is less common in India compared to other countries with high literacy rate. In this study OC was reported in $32.2 \%$ of women not using OCPs or consuming it for less than 5 years and $6.7 \%$ of women who were regularly using OCPs ( $\mathrm{p}=$ 0.041). Epidemiological literature over past several decades has consistently reported that consumption of OCPs causes a state of anovulation and is inversely associated with the risk of ovarian cancer with protective action increasing with duration of use. ${ }^{21}$ There is an increased risk of $\mathrm{OC}$ in obese women, which could be due to aromatisation of androgens into oestrogen in peripheral fat. ${ }^{22}$ Association of obesity and OC is a wellaccepted phenomenon in all populations. We correlated BMI with presence or absence of malignancy. OC was documented in $20 \%, 18.2 \%, 36.4 \%$ and $33.3 \%$ of underweight, normal weight, overweight and obese patients respectively in this study. While, ovarian cancer association consortium (OCAC) and the collaborative group on epidemiological studies of ovarian cancer observed that obesity is a risk factor for borderline and non- epithelial ovarian tumour and did not influence high grade serous cancers..$^{23,24}$ We have a little different observation, we found serous cystadenocarcinoma as a major contributor of $\mathrm{OC}$ in our study, these authors concluded presence of obesity association with nonepithelial OC (Table 1), $(\mathrm{p}=0.399)$. Prevalence of OC is more in postmenopausal age than premenopausal age. This was observed from presence of malignancy in $44.8 \%$ of patients in postmenopausal age group and $15.6 \%$ of premenopausal patients. Presence of premenopausal status (M-1) appears to have less likelihood of malignancy than postmenopausal (M-3) status (Table 2) $(\mathrm{p}=0.006)$. Other various studies have also concluded that $\mathrm{OC}$ is more common in postmenopausal age group. ${ }^{16,25-27}$ The main focus of this study is on RMI which is an integration of menopausal score, CA-125 level and USG score. In the present study menopausal score was the weakest constituent of RMI with sensitivity of $65 \%$ and specificity of $74 \%$ which is comparable with Jenitha B et al. ${ }^{28}$ Menopausal status alone cannot be used as an indicator of malignancy.

In our study CA-125 level has a varied range of 5.5$6680.0 \mathrm{U} / \mathrm{ml}$ and the mean value was $275.45 \mathrm{U} / \mathrm{ml}$ in all women with ovarian masses. In women with OC CA-125 had a high sensitivity of $90 \%$ with poor specificity of $74 \%$ (Table 3). Similar results were also obtained by several other studies. ${ }^{25,29,30}$ Thus, if the level of CA-125 is increased beyond $35 \mathrm{U} / \mathrm{ml}$ does not necessarily infer that the ovarian mass is malignant but if it is $<35 \mathrm{U} / \mathrm{ml}$ clearly denotes it is not malignant. The low specificity could be due to other benign causes of raised CA-125 in premenopausal women which increase its false positive rate. At the same time it is a good predictor and prognostic marker of OC.

USG is a widely accepted diagnostic modality which can accurately characterize $90 \%$ of ovarian masses. In the present study USG has a high sensitivity of $90 \%$ but poor specificity of $56 \%$ (Table 3 ) which is in accordance with Kestane I et al. ${ }^{30}$ It has a high false positive value which can lead to misdiagnosis of benign or borderline ovarian tumour as $\mathrm{OC}$ as the radiological findings between them show considerable overlap. ${ }^{31}$ If used as a single diagnostic indicator of OC it may cause unnecessary and morbid surgeries in malignant negative patients.

RMI is a multiparametric tool used to predict malignant ovarian disease. It overcomes high false positive rates of individual contributor of RMI i.e. menopausal score, USG score and CA-125 level. It transforms the morphological description of ovarian mass into objective numerical data. ${ }^{32}$ In benign tumours, the RMI had a range from 5.5 to 954 . Among the malignant tumours the range is from 10.90 to 44597.9. Average RMI for OC was 5717.3. Several studies have investigated the most accurate cut off value of RMI and found that value of > 200 has the best sensitivity, specificity, PPV and NPV of $89 \%-92 \%, 82 \%-96 \%, 62 \%-98 \%$ and $77 \%-98 \%$ respectively. ${ }^{33,34}$ In our study the cut off value of RMI was derived to be 250 (Figure 1) and the sensitivity, specificity, PPV and NPV of RMI were 90\%, 91\%, 78\% and $96 \%$ respectively (Table 3 ). In order to exclude 
malignancy, the false negative rate of scoring system should be 0 or near to $0 .{ }^{35}$. In our study among 74 cases, 2 patients had score $<250$ but were diagnosed with mucinous cystadenocarcinoma because the level of CA125 was within normal range which contributed to $2.7 \%$ of false negative rate. CA-125 has a limited role in diagnosing mucinous tumours when compared with nonmucinous epithelial tumor. ${ }^{30}$ Various prospective and retrospective studies have reported it to be best tool for triage and management of OC..$^{29,30}$ The minimum USG score was 0 in previous other studies which brought the product of $\mathrm{RMI}=0 .{ }^{5},{ }^{29}$ It was the major contribution of high false negative rate and low sensitivity of RMI in these studies. But in present study ovarian neoplasm with no USG parameters the $U=1$ similar to various other studies. ${ }^{16,28,30,34,36}$ Its utility as diagnostic tool has been found to be statistically significant (Table $2, \mathrm{P}=0.00$ ). In India patients defer repetitive radiological investigations due to lack of knowledge and financial limitations. RMI is a feasible and easily applicable device even in centres which do not have facilities of CT scan and MRI. Referral of patients with $\mathrm{RMI} \geq 250$ to specialized oncology centres is essential as the primary debulking surgery plays a great role in deciding prognosis of OC. ${ }^{5}$

\section{CONCLUSION}

Risk of malignancy index is a simple tool and with its high diagnostic efficiency can be used in daily clinical practise for preoperative evaluation of ovarian masses. With the high specificity it can not only discriminate benign from malignant OC but also decide for referral of malignant masses to gynaecology oncosurgeon when it is in operable state. The study findings clearly withstand that the validity of RMI is higher than its individual parameter in diagnosing ovarian tumour.

\section{ACKNOWLEDGMENTS}

Authors would like to thank Medical Director, Dr. V.K. Mahadik for allowing us to carry out the study and Department of Pathology and Radiology for their support for giving back up for investigations.

Funding: No funding sources Conflict of interest: None declared

Ethical approval: The study was approved by the Institutional Ethics Committee

\section{REFERENCES}

1. Rafii A, Halabi NM, Malek JA. High-prevalence and broad spectrum of Cell Adhesion and Extracellular Matrix gene pathway mutations in epithelial ovarian cancer. J Clin Bio Informa. 2012;2(1):15.

2. Rao PS, Bala R, Prajwal S. Risk of malignancy index in ovarian tumour for predicting ovarian malignancy by using Jacob's score. Int $\mathbf{J}$ Reprod Contracept Obstet Gynecol. 2017;6:1318-25.
3. Consolidated Report of Population Based Cancer Registries 2001-2004. National Cancer Registry Program. Indian Council of Medical Research. Bangalore; 2006. Available at: http://www.ncdirindia.org/ncrp/PBCR_2006_2008/P reliminary _Pages.pdf. Accessed $27^{\text {th }}$ July 2019.

4. Three-year report of population-based cancer registries 2012-2014: Incidence, distribution, trends in incidence rates and projections of burden of cancer. Bengaluru, India: National Centre for Disease Informatics and Research, National Cancer Registry Programme, and Indian Council Medical Research. Available at: http://www.ncrpindia.org/ALL_NCRP_ REPORTS/PBCR_REPORT_2012_2014/ALL_CON TEN T/Printed_Version.htm. Accessed $10^{\text {th }}$ July 2019.

5. Yelikar KA, Deshpande SS, Nanaware SS, Pagare SB. Evaluation of the validity of risk malignancy index in clinically diagnosed ovarian masses and to compare it with the validity of individual constituent parameter of risk malignancy index. Int $\mathbf{J}$ Reprod Contracept Obstet Gynecol. 2016;5:460-4.

6. Buys S, Partridge E, Greene M. Ovarian cancer screening in the prostate, lung, colorectal and ovarian (PLCO) cancer screening trial: findings from the initial screen of a randomized trial. Am J Obstet Gynecol. 2005;193(5):1630-9.

7. US Preventive Services Task Force. Screening for Ovarian Cancer. Available at: http://www.uspreventiveservicestaskforce.org/uspstf/ uspsovar.htm. Accessed $10^{\text {th }}$ January 2019.

8. Timmerman D, Valentin L, Bourne TH, Collins WP, Verrelst H, Vergote I, et al. Terms, definitions and measurements to describe the sonographic features of adnexal tumors: a consensus opinion from the International Ovarian Tumour Analysis (IOTA) Group. Ultrasound Obstet Gynecol. 2000;16:500-5.

9. Jacobs I, Oram D, Fairbanks J, Turner J, Frost C, Grudzinskas JG. A risk of malignancy index incorporating CA-125, ultrasound and menopausal status for the accurate preoperative diagnosis of ovarian cancer. BJOG. 1990;97:922-9.

10. Tingulstad S, Hagen B, Skjeldestad F, Onsrud M, Kiserud T, Halvorsen T, et al. Evaluation of a risk of malignancy index based on serum CA125, ultrasound findings and menopausal status in the preoperative diagnosis of pelvic masses. BJOG. 1996;103(8):826-31.

11. Tingulstad S, Hagen B, Skjeldestad FE, Halvorsen T, Nustad K, Onsrud M. The risk-of-malignancy index to evaluate potential ovarian cancers in local hospitals. Obstet Gynecol. 1999;93:448-52.

12. Nuttall FQ. Body mass index: obesity, BMI, and health: a critical review frank. Nutr Today. 2015;50(3):117-28.

13. Patel MD. Practical approach to the adnexal mass. Radiol Clin North Am. 2006;44:879-99. 
14. Valentin L. Use of morphology to characterize and manage common adnexal masses. Best Pract Res Clin Obstet Gynaecol. 2004;18:71-89.

15. Pepin K, del Carmen M, Brown A, Dizon, DS. CA 125 and epithelial ovarian cancer: role in screening, diagnosis, and surveillance. Am J Hematol Onc. 2014;10(6):22-9.

16. Radhamani S, Akhila MV. Evaluation of adnexal masses - correlation of clinical, sonological and histopathological findings in adnexal masses. Int $\mathrm{J}$ Sci Stud. 2017;4(11):88-92.

17. Adami HO, Lambe M, Persson I, Ekbom A, Adami HO, Hsieh CC, et al. Parity, age at first childbirth, and risk of ovarian cancer. Lancet. 1994;344:1250-4.

18. Whittemore AS, Harris R, Itnyre J. Characteristics relating to ovarian cancer risk: collaborative analysis of 12 US case-control studies. II. Invasive epithelial ovarian cancers in white women. Collaborative Ovarian Cancer Group. Am J Epidemiol. 1992;136:1184-203.

19. Moorman PG, Alberg AJ, Bandera EV, BarnholtzSloan J, Bondy M, Cote ML, et al. Reproductive factors and ovarian cancer risk in African-American women. Ann Epidemiol. 2016;26:654-62.

20. Gay GMW, Lim JSP, Chay WY, Chow KY, Tan MH, Lim WY. Reproductive factors, adiposity, breastfeeding and their associations with ovarian cancer in an Asian cohort. Cancer Cause Control. 2015;26:1561-73.

21. Tsilidis KK, Allen NE, Key TJ. Oral contraceptive use and reproductive factors and risk of ovarian cancer in the European Prospective Investigation into Cancer and Nutrition. Br J Cancer. 2011;105:143642.

22. Olsen CM, Green AC, Whiteman DC, Sadeghi S, Kolahdooz F, Webb PM. Obesity and the risk of epithelial ovarian cancer: a systematic review and meta-analysis. Eur J Cancer. 2007;43:690-709.

23. Olsen CM, Nagle CM, Whiteman DC, Ness R, Pearce CL, Pike MC, et al. Obesity and risk of ovarian cancer subtypes: evidence from the Ovarian Cancer Association Consortium. Endocr Relat Cancer. 2013;20:251-62.

24. Collaborative Group on Epidemiological Studies of Ovarian Cancer. Ovarian cancer and body size: individual participant meta-analysis including 25 , 157 women with ovarian cancer from 47 epidemiological studies. PLoS Med. 2012;9:e1001200.

25. Dora SK, Dandapat AB, Pande B, Hota JP. A prospective study to evaluate the risk malignancy index and its diagnostic implication in patients with suspected ovarian mass. J Ovarian Res. 2017;10(1):55.

26. Mondal SK, Banyopadhyay R, Nag DR, Roychowdhury S, Mondal PK, Sinha SK. Histologic pattern, bilaterality and clinical evaluation of 957 ovarian neoplasms: A 10-year study in a tertiary hospital of eastern India. J Cancer Res Ther. 2011;7:433-7.

27. Fang S, Shouzhen C, Yifei G, Xujing D, Qi C. The prevalence of malignant and borderline ovarian cancer in pre- and post-menopausal Chinese women. Oncotarget. 2017;8(46):80589-94.

28. Jenitha B, Subbiah M. Diagnostic value of risk malignancy index (RMI) for detection of malignancies in clinically diagnosed ovarian masses and to evaluate the validity of individual constituent parameter of risk malignancy index. Int J Reprod Contracept Obstet Gynecol. 2019;8:1558-62.

29. Simsek HS, Tokmak A, Ozgu E, Doganay M, Danisman N, Erkaya S, Gungor T. Role of a risk of malignancy index in clinical approaches to adnexal masses. Asian Pac J Cancer Prev. 2014;15(18):77937.

30. Kestane I, Senol T, Kahramanoglu I, Kestane D. The use of risk of malignancy index for adnexal masses. Gynecol Obstet. 2014;4:226.

31. Varras M. Benefits and limitations of ultrasonographic evaluation of uterine adnexal lesions in early detection of ovarian cancer. Clin Exp Obstet Gynecol. 2004;31(2):85-98.

32. Javdekar R, Maitra N. Risk of malignancy index (RMI) in evaluation of adnexal mass. J Obstet Gynaecol India. 2015;65(2):117-21.

33. Park JW, Hwang SO, Park JH, Lee BI, Lee JH. Discrimination between benign and malignant pelvic masses using the risk of malignancy index 1. J Korean Soc Menopause. 2013;19(1):18-25.

34. Ashrafgangooei T, Rezaeezadeh M. Risk of malignancy index in preoperative evaluation of pelvic masses. Asian Pac J Cancer Prev. 2011;12(7):1727-30.

35. Harry VN, Narayansingh GV, Parkin DE. The risk of malignancy index for ovarian tumors in Northeast Scotland- a population-based study. Scott Med J. 2009;54(2):21-3

36. Vasudevan JA, Nair V, Sukumaran S. Evaluation of risk of malignancy index in the preoperative assessment of ovarian tumors: Study from a tertiary care center. Saudi J Health Sci. 2016;5:67-71.

Cite this article as: Mahadik K, Singh N, Swami MB. Study of validity of risk of malignancy index in perimenopausal women with ovarian mass in a tertiary care hospital in India. Int J Reprod Contracept Obstet Gynecol 2020;9:588-94. 